\title{
Highly Compact Design of Trimmed Patch with Modified Partial Ground Structure for Extreme-Wideband Systems
}

\author{
Haitham Alsaif \\ Electrical Engineering Department \\ University of Hail \\ Hail, Saudi Arabia \\ hal-saif@hotmail.com
}

\begin{abstract}
In this paper, a novel highly compact microstrip monopole antenna with adjusted ground plane for ultrawideband (UWB) applications is proposed. The patch antenna is composed of a trimmed radiator and rectangular ground plane with four slots providing relatively extreme wide operating frequency from 2.8 till $16.2 \mathrm{GHz}$ based on $-10 \mathrm{~dB}$ criteria. The high matching impedance in the design results in ultra-wide bandwidth that covers the entire BW allocated by FCC for UWB applications. At the same time, the presented antenna is distinguished by significantly miniaturized structure with total size of $13 \mathrm{~mm} \times 10 \mathrm{~mm}$ printed on a substrate material of Rogers Duriod RT $5880 \mathrm{LZ}$ with relative permittivity of $\varepsilon_{\mathrm{r}}=1.9$ and loss tangent $\delta$ of 0.0009 . The suggested antenna is appropriate for miniature wireless gadgets. The patch has been investigated, and optimized in terms of operating frequency, impedance matching, radiation characteristics, structure size, and fabrication cost.
\end{abstract}

Keywords-compact; planar; antenna; wide operating frequency

\section{INTRODUCTION}

In recent years, ultra-wide band (UWB) wireless technology has remarkable attention because of several significant merits. These applications are able to provide extreme high data rates during their wide operating frequency using low levels of transmitted power. Thus, introducing new designs of compact planar UWB patches has played an essential part in gaining high performance features with regard to impedance matching, radiation pattern, and structure size. Furthermore, for commercial reasons, these designs should have low fabrication cost minimized and physical size $[1,16]$. Attributable to these characteristics, printed planar antennas have high attraction for short range communication systems. Several UWB monopole designs for instance elliptical shape, U-shape, ring, circular shape, and many others have been suggested and investigated in which the wide operating frequencies are achieved by different forms of radiating structures [2-12]. However, shrinkage in the designs structure sizes is a challenging matter as it is straightly linked to the length of the longest surface current at the lowermost edge of the operating frequency range [13]. Most of the formerly proposed ultra-wide patches have comparatively large physical size if not having nonplanar structures while many wireless systems for instance the radio frequency imaging applications necessitate planar structures. This is because miniaturized size antennas are easy to be inserted inside such systems. Moreover, numerous published planar UWB antennas' radiation pattern contain noticeable distortions in over their wide bandwidth. Besides, in several monopole designs, the operating frequency does not contain the entire bandwidth from $3.1 \mathrm{GHz}$ to 10.6 $\mathrm{GHz}$ assigned by Federal Communication Commission (FCC) for these applications [14]. Hence, the key objective of the presented planar design is accomplishing a highly compact monopole and ultra-high impedance bandwidth without any sacrifices in the other parameters characteristics so as to satisfy the main necessities for UWB wireless systems. The proposed antenna is well appropriate for applications of short ranges indoor UWB wireless communications. In the next section, the proposed compact patch is presented with parametric studies in details.

\section{PROPOSED MONOPOLE STRUCTURE}

Final geometry and fabricated prototype views of the designed patch are displayed in Figure 1 and labelled with dimensions. The patch antenna's microstrip feeding line has a characteristics impedance of $50 \Omega$ and printed on a $0.9 \mathrm{~mm}$ thick Rogers Duriod RT 5880 LZ substrate with relative permittivity of $\varepsilon_{\mathrm{r}}=1.9$ and loss tangent $\delta$ of 0.0009 . The design has a vitally miniaturized structure with total size of $10 \times 13$ $\mathrm{mm}^{2}$. Therefore, the monopole is more appropriate for small size ultra-wideband devices in addition to economizing space for other wireless system components. The microstrip line that has a length of $6.5 \mathrm{~mm}$ and $1.8 \mathrm{~mm}$ width feeds the trimmed rectangular radiator as clarified in Figure 1. As shown in Table $\mathrm{I}$, the partial modified ground plane $\left(3 \times 10 \mathrm{~mm}^{2}\right)$ is patched on the rear side of the substrate. The ground carries four I-shape slots that lead to a defected ground structure or DGS. This is in order to improve bandwidth performance and boost the antenna impedance matching. DGS approach has been applied at this antenna in order to increase current path length which results into wider operating frequency whereas the structure is retained very small. Table I shows extra information about the design 
parameters. The presented planar design has been studied and investigated with industrial simulation code named as Computer Simulation Technology Microwave Studio or CST. Then, it was fabricated and experimentally measured.

TABLE I. THE PROPOSED UWB MONOPOLE PARAMETERS IN MM

\begin{tabular}{|c|c|c|c|c|c|}
\hline Dimension & $\mathbf{L}$ & $\mathbf{W}$ & $\mathbf{H}$ & $\mathbf{W}_{\mathbf{f}}$ & $\mathbf{L}_{\mathbf{f}}$ \\
\hline Value in $\mathbf{m m}$ & 13 & 10 & 0.9 & 1.8 & 6.5 \\
\hline Dimension & $\mathrm{W}_{\mathrm{p}}$ & $\mathrm{W}_{\mathrm{s}}$ & $\mathrm{W}_{\mathrm{g}}$ & $\mathrm{L}_{\mathrm{s}}$ & $\mathrm{L}_{\mathrm{p}}$ \\
\hline Value in $\mathbf{m m}$ & 7 & 2 & 2 & 2 & 3.5 \\
\hline Dimension & $\mathrm{L}_{\mathrm{g}}$ & $\mathrm{L}_{\mathrm{g} 1}$ & $\mathrm{~L}_{\mathrm{g} 2}$ & $\mathrm{~W}_{\mathrm{s}}$ & $\mathrm{W}_{\mathrm{p}}$ \\
\hline Value in $\mathbf{m m}$ & 3 & 2.8 & 2.5 & 2 & 7 \\
\hline
\end{tabular}

\section{SIMULATION RESULTS AND EXPERIMENTAL PARAMETERS}

Narrow bandwidth or single resonant frequency in general is created by the simple patch antennas using a single resonant frequency. Thus, having numerous overlapped resonant frequencies will result in ultra-wide bandwidths (UWB). Designing UWB patch is based on the concept of forming resonant frequencies overlapping between them, which leads to wide bandwidths [15]. The proposed miniaturized monopole bandwidth contains two interfered resonant frequencies (5.1 and $9.5 \mathrm{GHz}$ ), through which an extreme wide operating frequency is modeled as revealed Figure 2. The figure shows both simulated and experimentally measured S11 (dB) versus frequency $(\mathrm{GHz})$. It can clearly be spotted that the design is illustrious by its ultra-wide operating frequency, that is from $2.8 \mathrm{GHz}$ up to $16.2 \mathrm{GHz}$ based on $-10 \mathrm{~dB}$ standard. Both simulated and measured S11 show good agreement and only minor differences due to common reasons such as fabrication tolerance, soldering effects, etc. The parametric and substrate materials studies of the presented design have been performed with respect to bandwidth and S11 parameter as part of the antenna analysis and optimization process. S11 is plotted in Figure 3 as a function of operating frequency for some commonly used substrate materials such as Polyimide, FR4, and Rogers Duroid RT5880LZ with relative permittivity $\varepsilon_{\mathrm{r}}$ of $3.5,4.3$, and 1.9, respectively. The proposed antenna is characterized by very high impedance matching using Rogers Duroid RT5880LZ which turns into enhanced reflection coefficient and wider bandwidth. This material has the lowest Rogers RT dielectric constant with very light weight. Moreover, the partial ground plane dimensions were analyzed and investigated. The length $\left(\mathrm{L}_{\mathrm{g}}\right)$ has high effect on the patch results. For this design, it has been found that $3 \mathrm{~mm}$ long will introduce low power loss. In other words, that is extreme wide bandwidth and best impedance matching compared to $3.5 \mathrm{~mm}$ and $4 \mathrm{~mm}$ ground planes long. Additionally, the second resonant frequency $9.5 \mathrm{GHz}$ appears noticeably in comparison with the other lengths as demonstrated in Figure 4. Also, S11 as a function of frequency for the design with and without slots on the partial ground plane are presented in Figure 5.

Using the defected ground structure or DGS technique by placing four I-shape slots improves the bandwidth significantly. Besides, microstrip feeding line width parameter plays crucial role in forming the ultra wide bandwidth as revealed in Figure 6 which illustrates S11 or reflection coefficient versus frequency for several wf values. After investigation, having feeding line $1.8 \mathrm{~mm}$ wide results into very low values of S11 parameter reaches $-33 \mathrm{~dB}$ and high impedance matching. In other words, matching between the radiator and the feeding line translated to more power transferred to the antenna, so the reflected power is reduced to less than $-0.1 \%$ whereas the accepted power is more than $99.9 \%$ [1]. Also, it is observed that wf is inversely related to the bandwidth in this design. In other words, as the feeding line becomes wider, the operating frequency shrink and it may end into a bandwidth not including whole UWB allocated by FCC $(3.1 \mathrm{GHz}$ to $10.6 \mathrm{GHz})$. Figure 7 displays the normalized radiation pattern to the peak value of the suggested patch monopole $5.1 \mathrm{GHz}$, and $9.5 \mathrm{GHz}$. It shows the radiation pattern at the two orthogonal planes, the elevation and azimuth plane ( $\mathrm{E}$ and $\mathrm{H}$ respectively) in polar forms. During the operating frequency, the radiation pattern at the $\mathrm{H}$ plane is omni-directional and the $\mathrm{E}$ plane is closely in bidirectional form with slight distortion. Accordingly, the proposed trimmed patch radiates in an omni-directional pattern which makes it independent of placement position during the complete bandwidth.

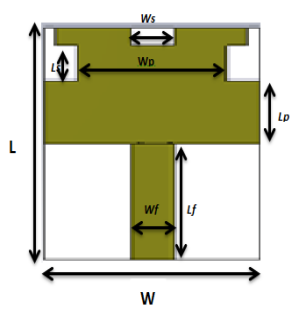

(a)

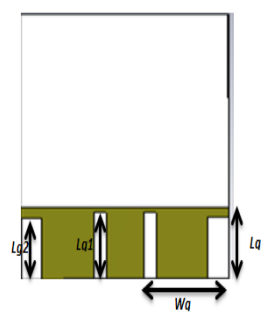

(b)

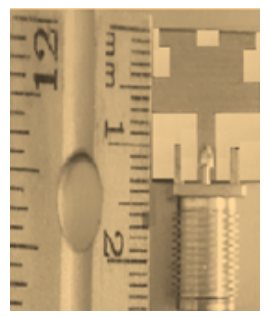

(c)
Fig. 1. The final geometry of the proposed design after optimization process: (a) Topside view labelled with parameters. (b) Backside view labelled with parameters. (c) Picture of the fabricated monopole.

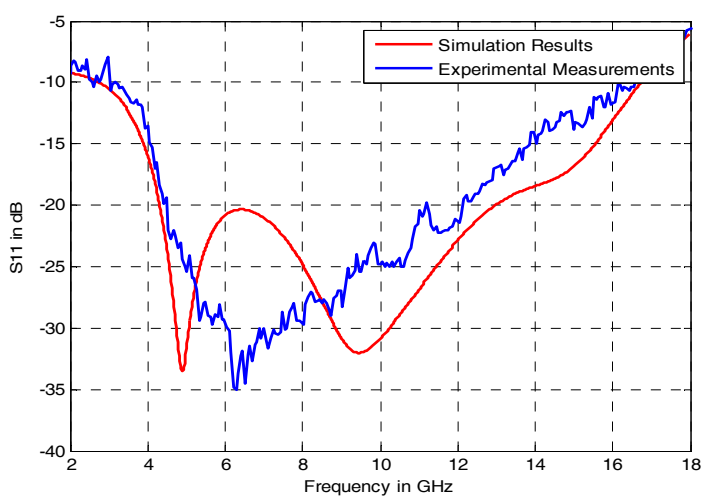

Fig. 2. Simulated and experimentally measured S11(dB) versus operating frequency $(\mathrm{GHz})$

\section{CONCLUSION}

A novel extremely miniaturized planar design is presented for ultra-wideband applications. The patch is miniaturized in structure and has a size of $13 \times 10 \times 0.9 \mathrm{~mm}^{3}$, with high performance features. The proposed monopole has an outstanding operating frequency that is from $2.8 \mathrm{GHz}$ to 16.2 
GHz which covers beyond the FCC UWB set for such systems. All through the bandwidth, the design radiates in approximate omni-directional pattern; accordingly, the monopole does not depend on the placement direction in the wireless system. In conclusion, the trimmed patch has competitive performance with many other larger size antennas, which makes it more appropriate for exceedingly compact communication systems.

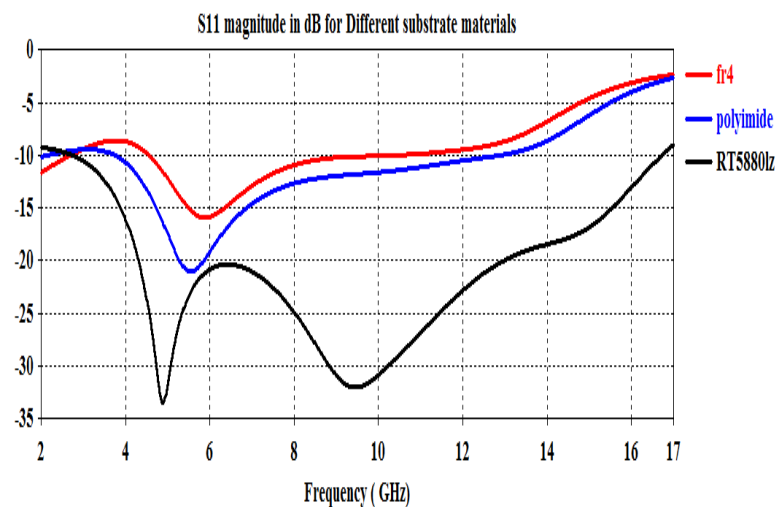

Fig. 3. $\quad \mathrm{S} 11(\mathrm{~dB})$ as a function of frequency $(\mathrm{GHz})$ using several substrate materials ( Polyamide, FR4, and Rogers RT 5880Lz)

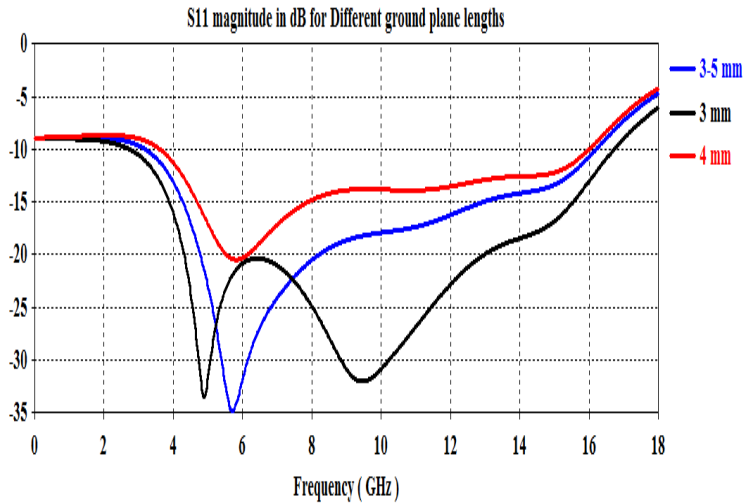

Fig. 4. The effect of the ground plane length parameter on the reflection coefficient in $\mathrm{dB}$

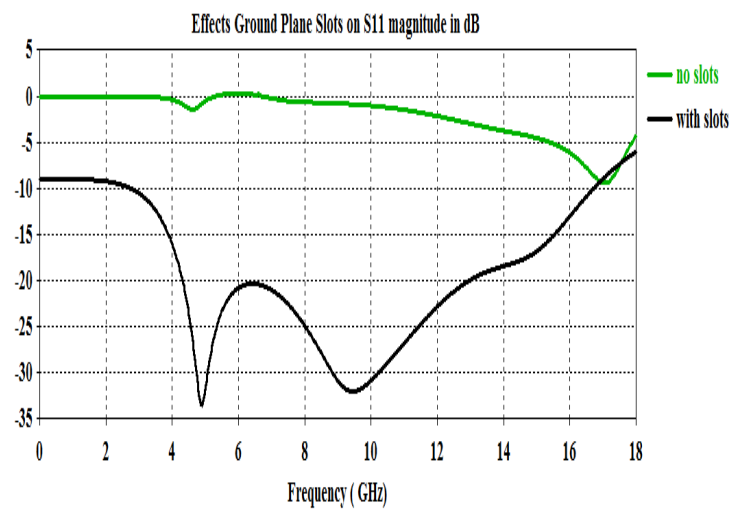

Fig. 5. The magnitude of $\mathrm{S} 11$ in $\mathrm{dB}$ for the proposed monopole with and without defected ground plane structure (DGS)

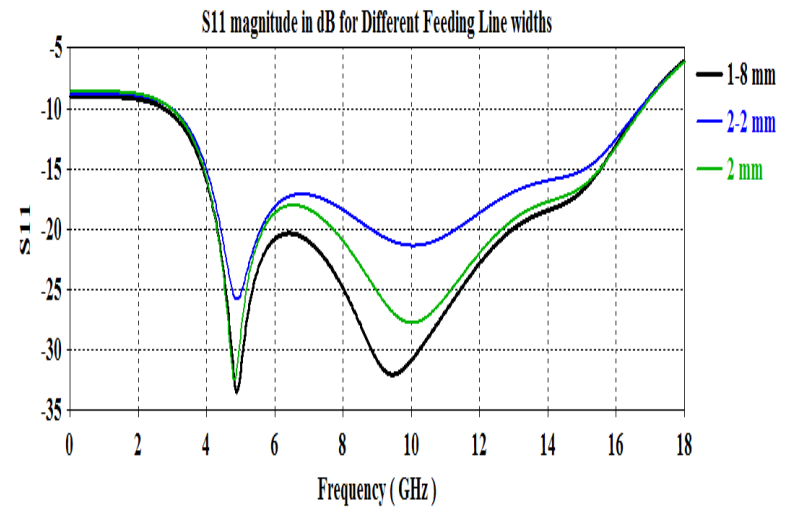

Fig. 6. Studying the width parameter of the feeding line (wf) for the presented design
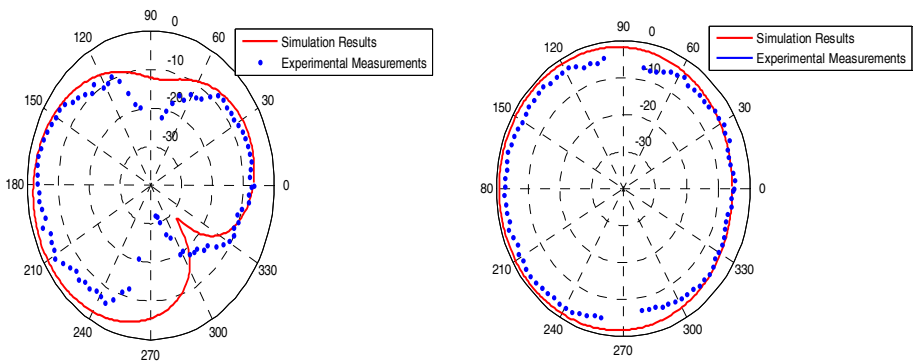

(a)
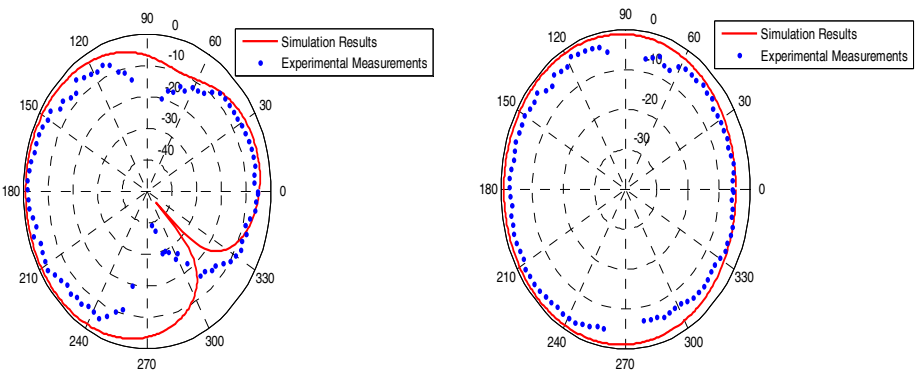

(b)

Fig. 7. The simulated and experimentally measured normalized radiation pattern for $\mathrm{E}$ and $\mathrm{H}$ planes in polar form at the resonant frequencies $(\mathrm{a}, \mathrm{b})$.

\section{ACKNOWLEDGMENT}

The author would like to thank the deanship of scientific research at the University of Hail in Saudi Arabia for supporting and funding this project (BA-1512).

\section{REFERENCES}

[1] H. Schantz, The Art and Science of Ultra Wideband Antennas. Norwood, MA: Artech House, 2005 W.-K. Chen, Linear Networks and Systems, Belmont, CA: Wadsworth, 1993, pp. 123-135

[2] Y. J. Ren, K. Chang, "Ultra-wideband planar elliptical ring antenna", Electronics Letters, Vol. 42, No. 8, pp. 447-449, Apr. 2006

[3] I. K. Joon, J. Yong, "Design of ultra wideband coplanar waveguide- fed LI-shape planar monopole antennas", IEEE Antennas and Wireless Propagation Letters, Vol. 6, pp. 383-387, 2007 
[4] A. S. Abbosh, M. E. Bialkowski, "Design of ultra wideband planar monopole antennas of circular and elliptical shape", IEEE Transactions on Antennas and Propagation, Vol. 56, No. 1, pp. 17-23, 2007

[5] M. Gopikrishna, D. D. Krishna, C. K. Aanandan, P. Mohanan, K. Vasudevan, "Compact linear tapered slot antenna for UWB applications", Electronics Letters, Vol. 44, No. 20, pp. 1174-1175, 2008

[6] M. N.Moghadasi, H. Rousta, B. S. Virdee, "Compact UWB planar monopole antenna", IEEE Antennas and Wireless Propagation Letters, Vol. 8, No. 22, pp. 1382-1385, 2009

[7] O. Ahmed, A. R. Sebak, "A printed monopole antenna with two steps and a circular slot for UWB applications", IEEE Antennas and Wireless Propagation Letters, Vol. 7, pp. 411-413, 2008

[8] C. Deng, Y. J. Xie, P. Li, "CPW-fed planar printed monopole antenna with impedance bandwidth enhanced”, IEEE Antennas and Wireless Propagation Letters, Vol. 8, pp. 1394-1397, 2009

[9] J. Liang, L. Guo, C. C. Chiau, X. Chen, C. G. Parini, "Study of CPW-fed circular disc monopole antenna for ultra wideband applications", IEE Proceedings - Microwaves, Antennas and Propagation., Vol. 152, No. 6, pp. 520-526, 2005

[10] D. T. Nguyen, D. H. Lee, H. C. Park, "Very compact printed triple bandnotched UWB antenna with quarter-wavelength slots", IEEE Antennas and Wireless Propagation Letters, Vol. 11, pp. 411-414, 2012
[11] E. S. Angelopoulos, A. Z. Anastopoulos, D. I. Kaklamani, A. A. Alexandridis, F. Lazarakis, K. Dangakis, "Circular and elliptical CPWfed slot and microstrip-fed antennas for ultrawideband applications", IEEE Antennas and Wireless Propagation Letters, Vol. 5, pp. 294-297, 2006

[12] E. Ebrahimi, O. Litschke, R. Baggen, P. S. Hall, "Isolation enhancement of planar disc antenna and ground plane in UWB applications", Electronics Letters, Vol. 46, No. 23, pp. 1539-1541, 2010

[13] K. Xu, Z. Zhu, H. Li, J. Huangfu, C. Li, L. Ran, “A Printed Single-Layer UWB Monopole Antenna With Extended Ground Plane Stubs", IEEE Antennas and Wireless Propagation Letters, Vol. 12, pp. 237-240, 2013

[14] Federal Communication Commission, First Report and Order, Revision of Part 15 of the Commission's Rules Regarding Ultra-Wideband Transmission System, FCC 02 48, 2002

[15] A. Gautam, S. Yadav, B. Kanaujia, "A CPW Fed Compact UWB Microstrip Antenna," IEEE Antennas and Wireless Propagation Letters, Vol. 12, pp. 151-154, 2013

[16] L. M. DeVito, “A versatile clock recovery architecture and monolithic implementation" in: B. Razavi, Monolithic phase-locked loops clock recovery circuits, Wiley-IEEE Press, 1996 